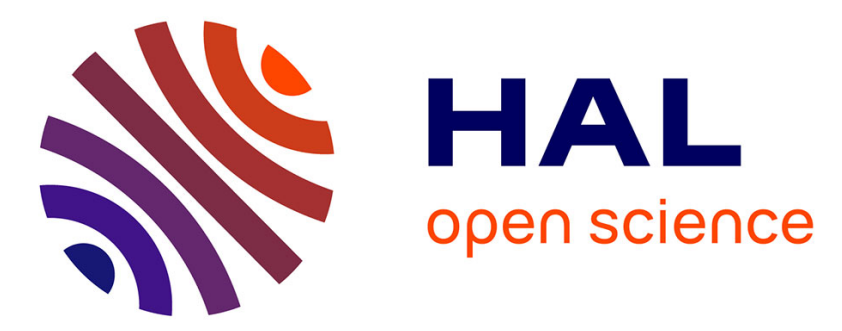

\title{
The Flexible Initiation Test (FIT): A new experimental test to characterize fracture initiation in mode $I$ at the free edge of bonded assemblies
}

Thanh Quang Bui, Aurelien Maurel-Pantel, Frédéric Mazerolle, Ch Hochard

\section{- To cite this version:}

Thanh Quang Bui, Aurelien Maurel-Pantel, Frédéric Mazerolle, Ch Hochard. The Flexible Initiation Test (FIT): A new experimental test to characterize fracture initiation in mode I at the free edge of bonded assemblies. International Journal of Adhesion and Adhesives, 2018, 84, pp.291 - 300. 10.1016/j.ijadhadh.2018.02.037 . hal-01777870

\section{HAL Id: hal-01777870 \\ https://hal.science/hal-01777870}

Submitted on 25 Apr 2018

HAL is a multi-disciplinary open access archive for the deposit and dissemination of scientific research documents, whether they are published or not. The documents may come from teaching and research institutions in France or abroad, or from public or private research centers.
L'archive ouverte pluridisciplinaire HAL, est destinée au dépôt et à la diffusion de documents scientifiques de niveau recherche, publiés ou non, émanant des établissements d'enseignement et de recherche français ou étrangers, des laboratoires publics ou privés. 
The Flexible Initiation Test (FIT): a new experimental test to characterize

fracture initiation in mode I at the free edge of bonded assemblies

Q. Bui, A. Maurel-Pantel, F. Mazerolle, C. Hochard

Corresponding author :

Aurelien MAUREL PANTEL Maître de Conférences

Dr. Ing. Mécanique \& Matériaux

Mobile: 06.85.95.13.91

$-$

Laboratoire de Mécanique et d'Acoustique

4 impasse Nikola TESLA CS 4000613453 MARSEILLE CEDEX 13

Tél: LMA 04.84.52.55.99

email: maurel@lma.cnrs-mrs.fr

web:lma.cnrs-mrs.fr 


\section{Abstract}

Direct bonding is based on molecular adhesion. This bonding technique consists to join two surfaces into direct contact without the use of any adhesives or additional material. This process requires clean surfaces with a nanometric roughness, sufficiently close together to initiate bonding. Mechanical characterization of this type of assembly with classical mechanical test as for instance wedge test, cleavage test or double shear test present a highly scattering on mechanical results. This paper presents the Flexible Initiation Test (FIT test), an original test designed to characterize fracture initiation in mode I, and to decrease scattering in fracture initiation load measurements, in particular for adhesive with brittle behavior. This new test has to take into account the industrial framework: to be easy to manufacture, easy to execute repeatedly and efficient to provide experimental data for numerical models (stress criteria applications for instance). The paper proceeds first with an explanation of the main initial ideas to introduce the concept of this new test. Next, a numerical analysis is proposed to validate the concept and to determine the optimal geometry of the tests. Then the experimental device is set up and the concept is validated on three different adhesives with the same substrate (a brittle cyanoacrylate adhesive, a ductile and a brittle epoxy adhesives). To conclude, the FIT test is applied on direct bonded samples (an extreme case nanometric interface and very brittle behavior) to determine the fracture initiation load and to compare scattering of measurements.

Keywords: fracture initiation test; mode I; brittle bonding; adhesives; direct bonding; 


\section{Introduction:}

Adhesive bonding presents many advantages compared to other joining methods such as riveting, welding or mechanical fastening. These advantages include the ability to bond different materials together, lower structural weight, lower fabrication cost, reduction in stress concentration, design flexibility and easy manufacturing. In fact, adhesive bonding is used in a wide range of industrial applications, such as construction, transportation, automotive, marine, electronics, aeronautics and aerospace. Adhesively bonded joints offer many advantages for the design of structures, but a lack of confidence currently limits the use of this technology [1-3].

Mechanical strength characterization of bonding surfaces is essential to improve integration of bonded assemblies in complex systems [3]. Within the frameworks of fracture mechanics and structure damage evolution tracking, two main issues are addressed: characterization of fracture initiation and fracture propagation in bonded assemblies. In literature many experiments characterizing fracture propagation have been described as in Ripling et al. [4]. These tests are really well known and numerous numerical and experimental results have been reported. There are also a number of tests available to characterize fracture initiation: the standard Single Lap Joint test in ASTM standard, the Thick Adhesive Shear test in ASTM standard, the simple tensile test on a two bonded cylinder assembly as in Berry [5], the three-point bending test as in McDevitt et al. [6], as well as more recent tests such as the ARCAN test [7]. However, all these tests exhibit a non-negligible scattering of results due to 
a strong sensitivity to defects, in particular for bonding with a brittle behavior. In bonded samples or assemblies, edge effects occur which mainly depend on the Young's moduli and Poison's ratio of both the adhesive and the substrates, as well as on the stiffness and geometries of the substrates. These effects can induce high stress concentrations, which affect the mechanical strength and generally lead to early rupture. The slightest defects in the adhesive or in the substrate can cause the breaking of the assembly, and that's why measurements of ultimate load failure exhibit large scatter. In their interesting and important work, Cognard et al. [8-10] and Davies et al. [11] have developed a process of sample geometry optimization to overcome this problem. The new modified ARCAN test allows better measurement reliability. To reduce the edge effects, a beak, machined with an angle of $45^{\circ}$, a blending radius of $0.8 \mathrm{~mm}$ and a convex shape, is imposed on the edge part of the adhesive. The introduction of a beak raises manufacturing and handling issues. These specific geometries are very difficult to reproduce in complex industrial structure assemblies, in particular on fused silicate substrate for direct bonding. Furthermore, the experimental results obtained for the epoxy resin Araldite ${ }^{\circledR} 420$ [12], for example, Cognard et al. [13] in their results still display residual scattering.

This paper reports on the research conducted within the framework of cooperation with the French National Center of Spatial Studies (CNES) concerning fused silica or Zerodur ${ }^{\circledR}$ direct bonding technology. Direct bonding consists in joining two surfaces without the use of any adhesive or additional material as described by Kendall [14]. Usually, by 
bringing two flats, well-polished surfaces into contact at room temperature, they locally attracted to each other by Van der Walls or hydrogen bonds and adhere or bond. The main applications are on silicon-on-insulator devices. Silicon based sensor and actuators, electronics substrates are other examples of wafer bond classic applications reported by Ventosa et al. [15]. Recently, this process has been used in the manufacturing of high performance optical system for terrestrial application such as Fabry-Perot interferometers, prism assemblies. Nowadays, direct bonding is of particular interest for spatial instrument applications. Indeed, this is a high-precision production process, and direct-bonded assemblies obtained present a dimensional stability (CTE) due to the absence of mechanical parts or glue. In addition, since no adhesive material is used in the process, the risks of contamination associated with degassing are avoided, which is another advantage in a spatial context. A first prototype has successfully passed the space environment tests (mechanical and thermal constraints) where the constraints involved (thermal fatigue, accelerations, vibrations, etc.) are very different from those encountered on Earth.

However, a better understanding of the assemblies' mechanical strength behaviour is required to validate the system life expectancy and to meet the European Space Agency standards. The mechanical strength of direct bonded interfaces depends on the interface defects and on the nature of the bonds involved as described Cocheteau et al. [16, 17]. Indeed, Liao et al. [18] explained that room temperature bonding needs flatness and roughness perfectly controlled, and no particles contaminations on surfaces. Room temperature bonding is usually relatively 
weak; consequently, for some applications, the bonded assemblies undergo an annealing treatment causing changes in the nature of bonds responsible for adhesion and thus strengthen the bond across the interface as explained in Kissinger et al. [19]. Direct bonding exhibit a brittle behavior and an interface thickness at molecular scale.

This paper presents an original test designed to characterize fracture initiation in mode I, and to decrease scattering in experimental results, in particular for direct bonding. This new test have to take into account the industrial framework: have to be easy to manufacture, easy to execute repeatedly, efficient to confront adhesive performance and to provide experimental data for numerical models. The final aim consist to develop a new experimental test to measure critical initiation load for brittle adhesive considering the extreme case of direct bonding interface (i.e. thickness interface at molecular scale), in order to be able to use these experimental results to apply stress criterion (point stress, average stress, or coupled criteria).

The paper proceeds first with an explanation of the main initial ideas to introduce the concept of this new test named FIT for Flexible Initiation Test. A numerical analysis is proposed to validate the concept of the experimental bench and determine the optimal geometry of the experimental device (Section 3). In section 4, the design of the new experimental bench is described and the concept is validated experimentally on three different adhesives with the same substrate: the Permabond 910 a brittle cyanoacrylate adhesive with a thickness of $0.01 \mathrm{~mm}$ [20]; the Scotch-Weld ${ }^{\text {TM }} 3 \mathrm{M} 2216 \mathrm{~B} / \mathrm{A}$ a ductile epoxy adhesive with a thickness of $0.1 \mathrm{~mm}$ [21]; and the Araldite ${ }^{\circledR}$ AV138M-1/ Hardener HV998 a brittle epoxy 
adhesive with a thickness of $0.1 \mathrm{~mm}$ [22]. In section 5, the direct bonding case is considered, the scattering of direct bonding critical initiation load measurement is compared. Finally, conclusions and prospects are drawn in Section 6. 


\section{New fracture initiation test in mode I}

In previous investigation, Cocheteau et al. [16] were performed a peel test and a modified cleavage test in order to determine the influence of the reinforced direct bonding process parameters on the bonding mechanical strength. The experiments were run on five fused silica samples for each condition. In the tensile testing machine, the sample was mounted and bonded between two aluminum mechanical parts, as related in Figure 1. For each sample, the critical initiation load was measured to characterize the bonding mechanical strength. Then to determine a stress value for the interface mechanical strength, a failure stress criteria is applied.

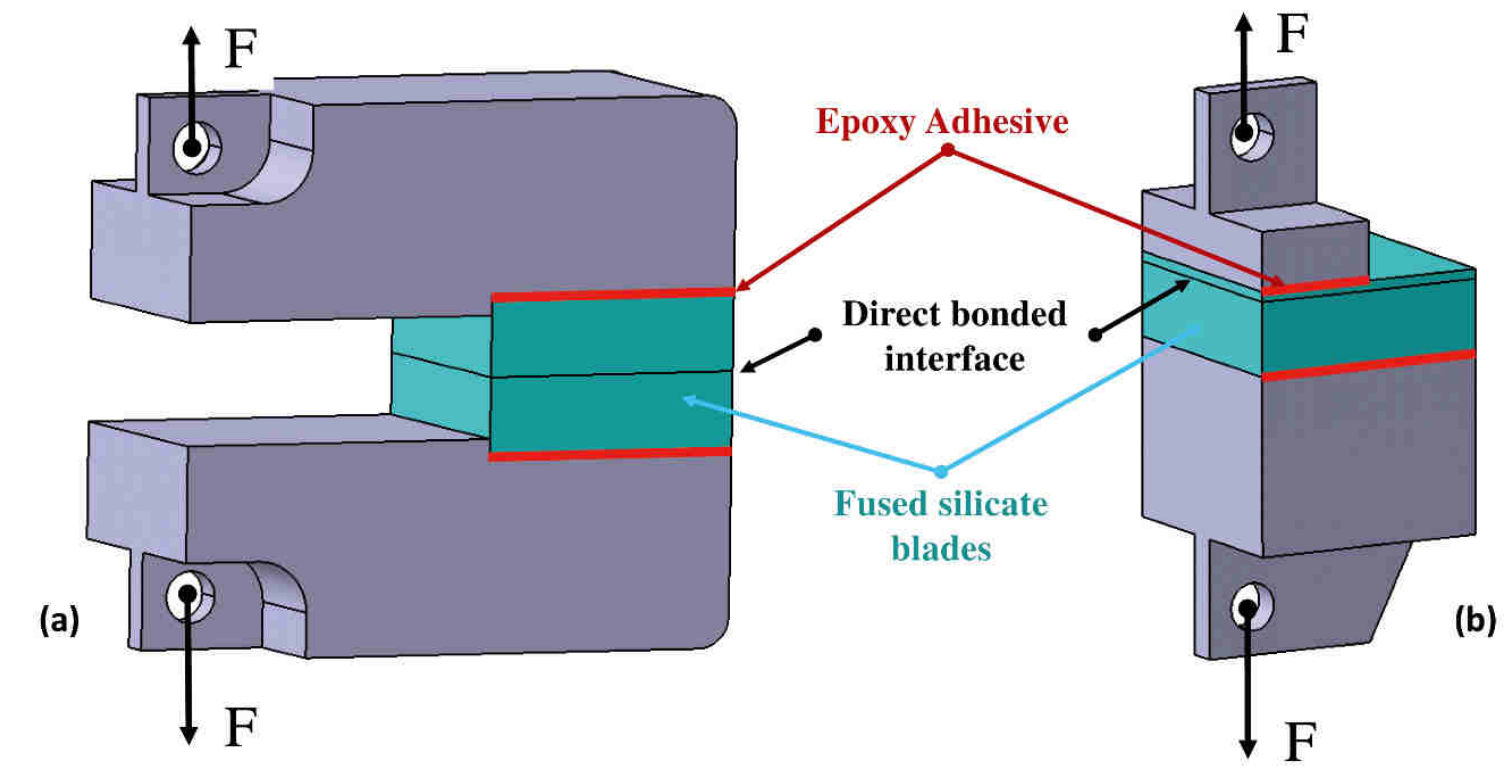

Figure 1. CAD of modified Cleavage test (a) and Peel test (b) experimental devices used to characterize direct bonding interface (sample sizes are $40 \mathrm{~mm} \times 40 \mathrm{~mm} \times 12,5 \mathrm{~mm}$ in (a) and $40 \mathrm{~mm} \times 40 \mathrm{~mm} \times 12,5 \& 1,7 \mathrm{~mm}$ in (b)). 
After the analysis of measurements, the scattering (standard deviation in \%) around the critical initiation load average value in these two tests is reported in Figure 2. A lower dispersion is observed for the modified cleavage test than for the peel test. We can see that for this modified cleavage test, the load application point is shifted from the bonding edge. This observation leads to determining the role played by the load application point position.

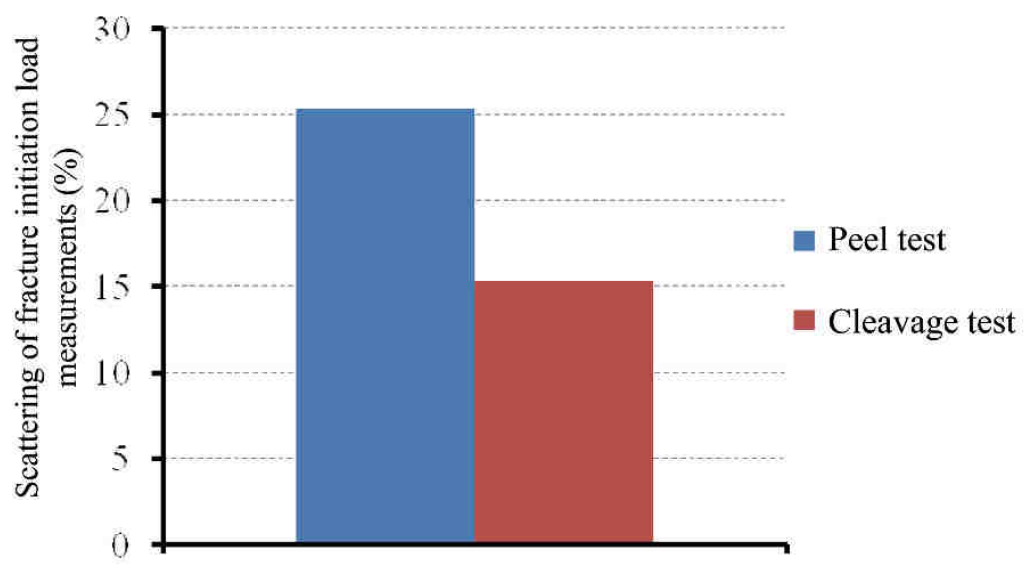

Figure 2. Percent of scattering around the critical initiation load average value for the peel test and the modified cleavage test used to characterize direct bonding interface.

In order to study the influence of the load application point position, the Double Cantilever Beam (DCB) classical test, used for crack propagation, is considered (Figure 3). Using the Euler-Bernoulli beam theory, the critical strain energy release rate can be expressed as follows:

$$
G_{I}=\frac{12 F^{2} a^{2}}{E b^{2} h^{3}}
$$


where $G_{I}$ is the critical strain energy release rate, $F$ the crack propagation load, $a$ the crack length distance measured between the vertical load line and the tip of crack on the edge of the specimen, $E$ the longitudinal modulus, $b$ the width and $h$ the thickness of the sample. With equation (1), the crack propagation load $F$ can be written as a function of the crack length $a$ with the following expression:

$$
F=\frac{1}{a} \sqrt{\frac{G_{I} E b^{2} h^{3}}{12}}
$$

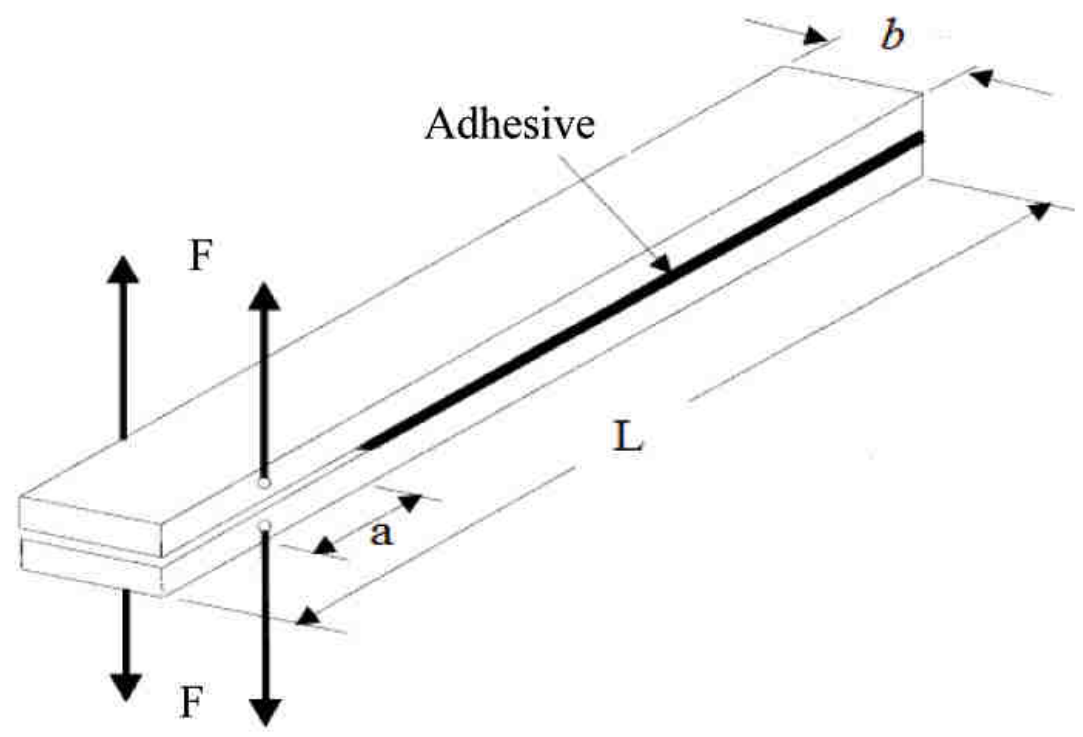

Figure 3. Picture of the classical DCB test.

If the critical strain energy release rate is assumed to be constant, the mathematical relation proposed in equation (2) describes the evolution of the crack propagation load as a function of the crack length (the curves are shown in Figure 4). Therefore, it should be noticed that the longer $a$ is, the smaller the load variation $\Delta F$ is with respect to $\Delta a$. Concerning the initiation 
test, we make an analogy between $\Delta a$ and inherent bonding defect close to the edge with different sizes. Based on this observation, we make the assumption that increasing $a$ will make it possible to decrease scattering of the test. We can remark that increasing the distance $a$ is equivalent to increasing the beam flexibility. In conclusion, the idea is to increase the flexibility of the beam to decrease scattering on fracture initiation load measurement.

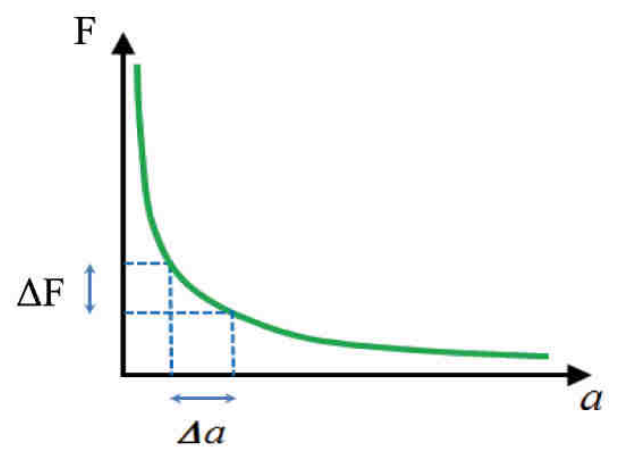

Figure 4. Evolution of the crack propagation load as a function of crack.

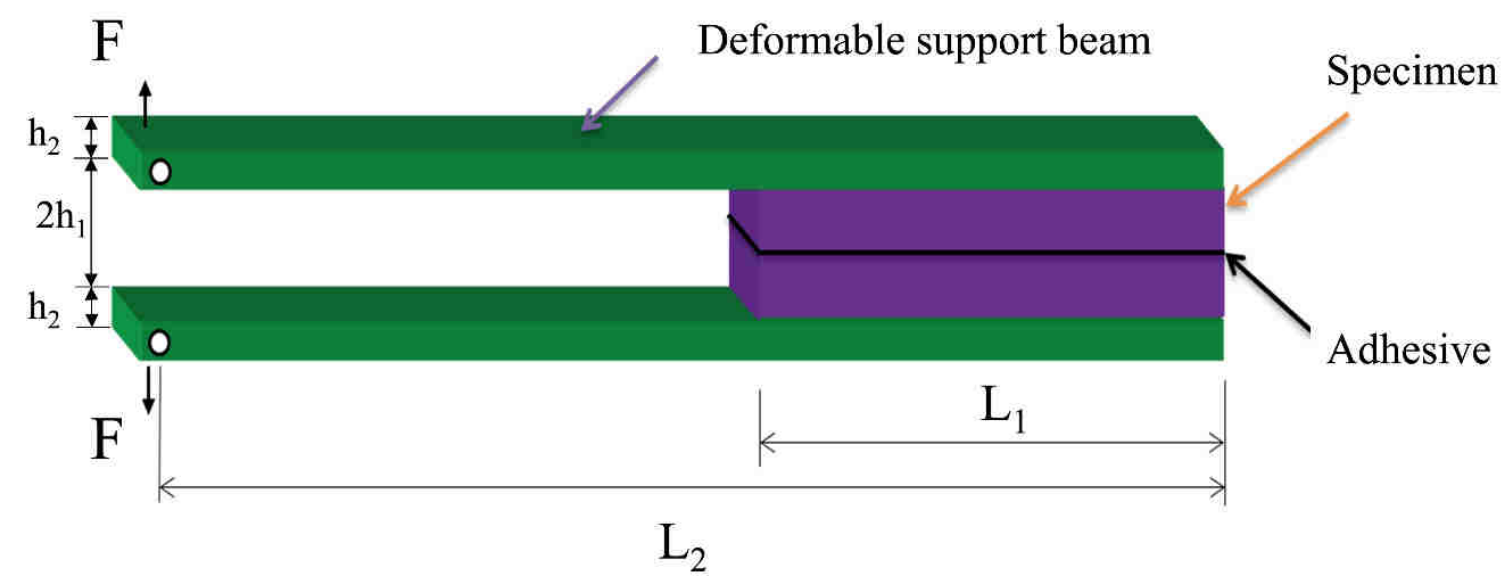

Figure 5. The FIT test: the Flexible Initiation Test proposed for the analysis of crack initiation in mode $\mathrm{I}$. 
The beam flexibility can be increased either by increasing the length or by decreasing the thickness of the beam. As related in Figure 5, a new experimental configuration with a deformable support beam is proposed. In this test, the sample (adhesive and substrate) is fixed on the support beam by means of a mechanical part or bonding interfaces. The load is imposed at the end of the deformable support beam. Load and displacements at the application point are measured during the test until fracture initiation. The parameters for the geometry of this test are $L_{1}$ the bond length, $h_{1}$ the sample's half thickness, $L_{2}$ the length of the deformable support beam, $h_{2}$ the thickness of the deformable support beam and $b$ the width of the experimental device. The flexibility can be adjusted by tuning $L_{2}$ and $h_{2}$. The opening forces $F$ are applied to the deformable support beams, the non-bonded part develops flexural stresses. The maximal value of the flexural stress in the support beam can write:

$$
\sigma_{\max }=\frac{6 F\left(L_{1}-L_{2}\right)}{b h_{2}^{2}}
$$

During the test we need to stay within the elastic range, the geometric condition on the support beam thickness $h_{2}$ can be written as:

$$
h_{2} \geq \sqrt{\frac{6 F\left(L_{1}-L_{2}\right) s}{b \sigma_{Y}}}
$$

with $\sigma_{Y}$ the yield stress of the support beam material and $s$ a safety factor on the yield stress (for instance in our case $s=2$ ). Then to maintain deformable support beams, we choose to define the following rules $\left(h_{1}\right.$ is practically chosen the smallest as possible): 


$$
h_{1}<h_{2}
$$

After the introduction of this new test, a numerical analysis is proposed to determine the efficiency of this new configuration to measure the fracture initiation critical load $F_{C}$. 


\section{Numerical analysis of the flexible initiation test:}

In this section, a preliminary 2D numerical simulation of the FIT is performed with the commercial finite element code ABAQUS 6.10 in order to define the optimal geometry to decrease the critical initiation load measurements scattering for a given bonded joint under static loading in mode I.

Table1 Mechanical properties of deformable support beam and substrate.

\begin{tabular}{c|c|c}
\hline $\mathrm{E}(\mathrm{GPa})$ & $\sigma_{Y}(\mathrm{MPa})$ & $v$ \\
\hline 70 & 210 & 0.33 \\
\hline
\end{tabular}

Table 2 Material parameters of the Hysol EA 9321 adhesive modelled in FEM simulations

\begin{tabular}{c|c|c|c}
\hline $\mathrm{E}(\mathrm{MPa})$ & $v$ & $\sigma_{C}(\mathrm{MPa})$ & $\mathrm{G}_{\mathrm{IC}}(\mathrm{N} / \mathrm{mm})$ \\
\hline 3970 & 0.36 & 46 & 0.45 \\
\hline
\end{tabular}

\subsection{Material parameters and geometry:}

In Figure 5, substrate and deformable support beam materials can be different as in the final application in section 5. In the case of adhesive characterization, the substrate and the beam can be in the same material. We chose to have the same material for the deformable support beam and the substrate: an aluminum-alloy 2014-T4 with an elastic and isotropic behavior. The mechanical properties used for the simulation are related in Table 1. It is assumed in 
simulations that the deformable support beam and the samples are machined in a single part as related in Figure 6.

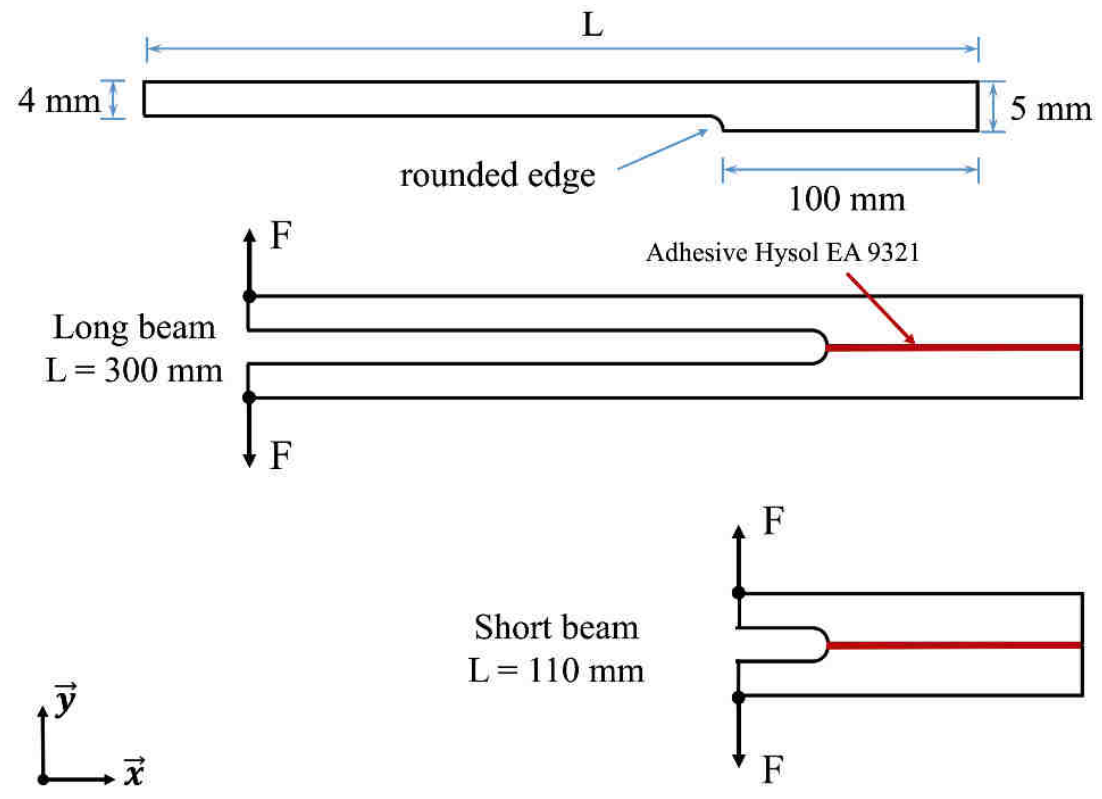

Figure 6. Geometry of the samples. And the two cases considered for the FEM simulation (long and short beam).

In simulations, the bonded joint considered, was the Hysol EA 9321 adhesive on an aluminum substrate. The adhesive material parameters used in FEM analysis were taken in Da Silva et al. paper [23]. The parameters are reported in Table 2. According to equation introduced in section 2, the thickness of deformable support beam and substrate were respectively set to: $h_{1}=1 \mathrm{~mm}$ and $h_{2}=4 \mathrm{~mm}$. In these preliminary investigation, the flexible initiation test configurations chosen for numerical simulations are: a sample with a rounded edge, and two different deformable backing beam lengths $(110 \mathrm{~mm}$ and $300 \mathrm{~mm})$ in order to analyze the influence of the beam flexibility on the scattering of fracture initiation load measurement. 
The rounded edge geometry is used to check the decreasing of scattering with the FIT test in this particular case (close to the industrial application). Indeed, in case of a round edge and in neglecting the adhesive thickness, the stress concentration is finite. The sample geometry and the bonded assembly are described in Figure 6.

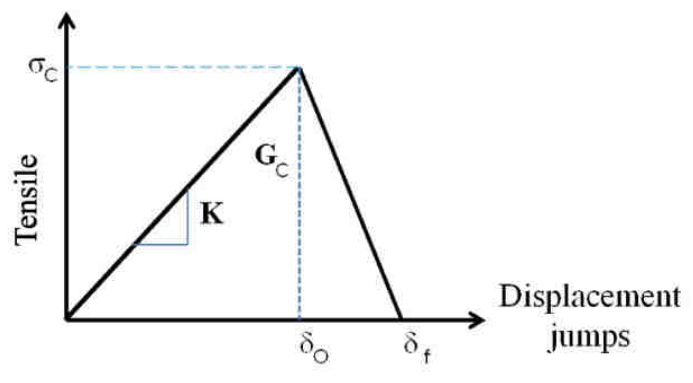

Figure 7. Description of the bilinear law used to model adhesive behavior in finite element simulations.

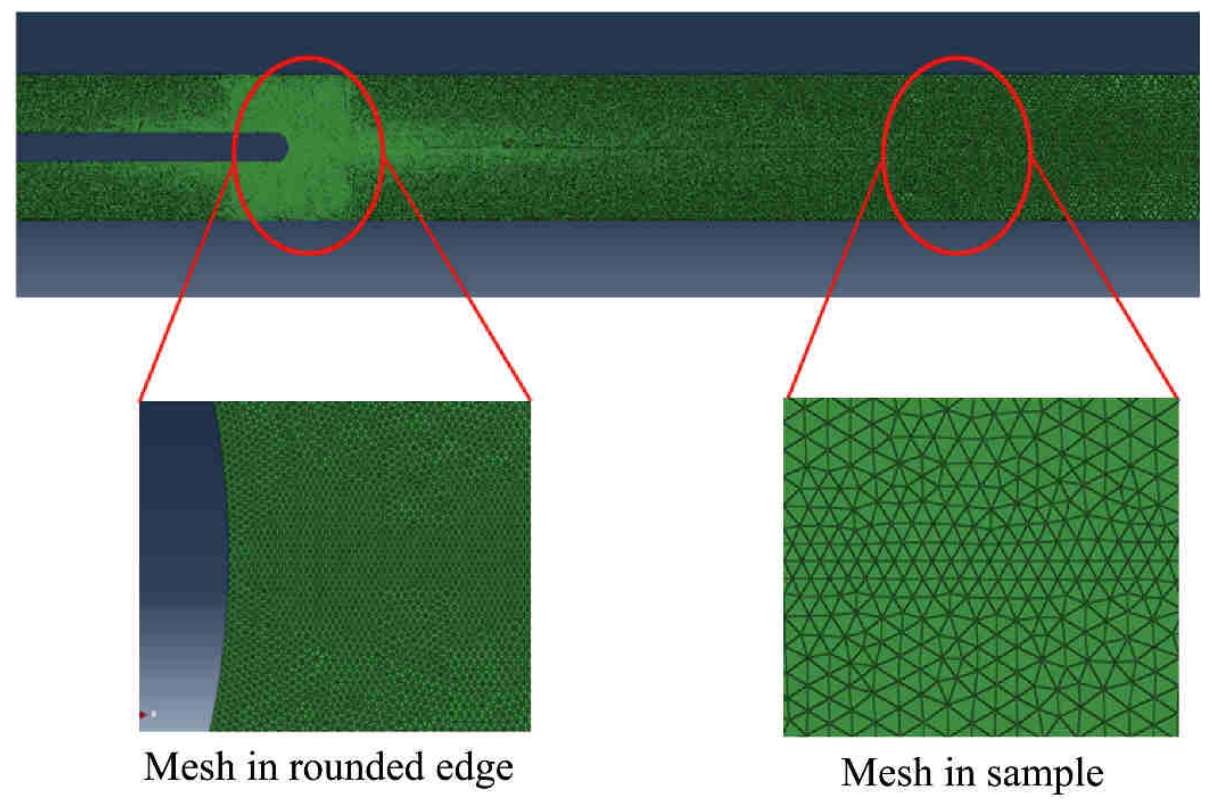

Figure 8. Mesh Configuration used in the preliminary simulation.

\subsection{Adhesive behavior and boundary conditions:}


In these simulations, cohesive zone models (CZMs) have been used to model adhesive mechanical behavior. The CZMs approach is one of the most commonly numerical methods used to investigate the failure of adhesive joints. This model is based on the assumption that a cohesive damage zone (or process zone) develops near the initiation zone at the crack tip generally. This zone can model the initiation of a micro crack. The cohesive zone model links tensile stress $\sigma$ to displacement jump or crack opening $\llbracket \delta \rrbracket$ at an interface where a crack initiates in the adhesive. Damage initiation occurs when the stress reaches the tensile strength. During the crack opening process, energy is dissipated, when total energy dissipated corresponds to the critical energy release rate $G_{C}$, the interface element fails and the crack propagates. In literature, many CZMs with damage law have been proposed (trapezoidal law, bilinear law, power law, exponential law, etc.). In these simulations, the bilinear law shown in Figure 7 is applied. The cohesive layer is modeled in Abaqus code with a four-node cohesive element $\mathrm{COH} 2 \mathrm{D} 4$, zero thickness is imposed, the solid substrates are modeled with twodimensional plane strain elements (CPE4 and CPE3 in ABAQUS), as shown in Figure 8. The problem is in plane, there is no boundary condition like in the experimental configuration, but there are two symmetrical loads applied at the tip of each flexible support beam in the vertical direction $\vec{y}$ as related in Figure 6 .

\subsection{Mesh Convergence}

First simulations have been performed to investigate mesh convergence. The cohesive element length and the mesh size is estimated from the length of the process zone at the crack 
tip. Turon et al. [24] proposed to determine the size of the fracture process zone $l_{c z}$ as a material property given by the following expression:

$$
l_{c z}=M E \frac{G_{C}}{\sigma_{C}^{2}}
$$

where $E$ is the Young modulus, $G_{C}$ is the critical energy release rate, $\sigma_{c}$ is the interface mechanical strength, and $M$ is a parameter which is dependent on the cohesive zone model; its value ranges from 0.21 to 1.0 .

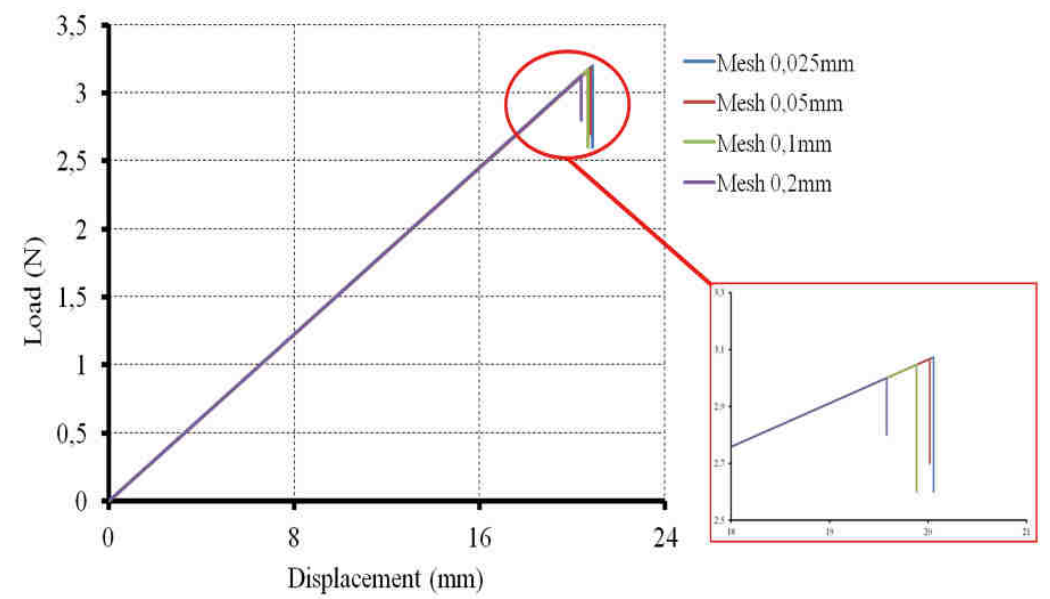

Figure 9. Influence of the mesh size on the macroscopic response (numerical fracture initiation load) using a bilinear CZM law.

The mesh size is calculated with the following expression:

$$
l_{e}=\frac{l_{c z}}{N}
$$


where $\mathrm{N}$ is the number of cohesive elements needed in the process zone; its value ranges from 3 to 10 as reported in Moës et al. [25]. According to Eq. (6) and Eq. (7), the mesh size ranges from $0.0248 \mathrm{~mm}$ to $0.23 \mathrm{~mm}$. Thus, the following mesh sizes, $0.2 \mathrm{~mm}, 0.1 \mathrm{~mm}, 0.05 \mathrm{~mm}$ and $0.025 \mathrm{~mm}$, were chosen to test the mesh convergence. Mesh size optimization is performed in order to improve the numerical prediction on the bonding edge and to decrease the calculation time, as related in Figure 8. The numerical load-displacement curves are described in Figure 9. The results indicate that a mesh size of $l_{e} \leq \mathbf{0 . 0 5} \mathbf{m m}$ is necessary to obtain the converged solution. All the simulations are conducted with a mesh size of $\mathbf{0 . 0 5} \mathbf{m m}$.

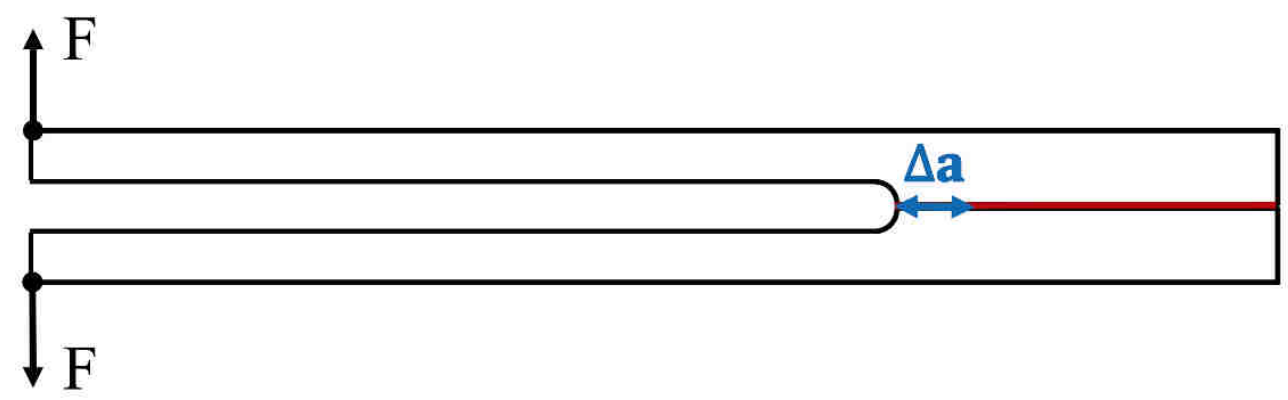

Figure 10. Introduction of a defect in simulation of the flexible initiation test as a small pre$\operatorname{crack}(\Delta \mathrm{a})$.

\subsection{Numerical Results:}

In order to investigate the influence of a simulated defects on scattering in bonding joint strength, two flexible initiation test configurations is simulated: the first one in the case of long deformable support beams $(\mathrm{L}=300 \mathrm{~mm})$ and the second one in the case of very short deformable support beams $(\mathrm{L}=110 \mathrm{~mm})$, as described in Figure 6 . The defect is represented 
by a small pre-crack $(\Delta \mathrm{a})$ as related in Figure 10. Four different sizes of defect are considered for each length of deformable support beam. The flexible initiation test is simulated and critical fracture initiation loads are measured. The numerical load-displacement curves are reported in Figure 11.
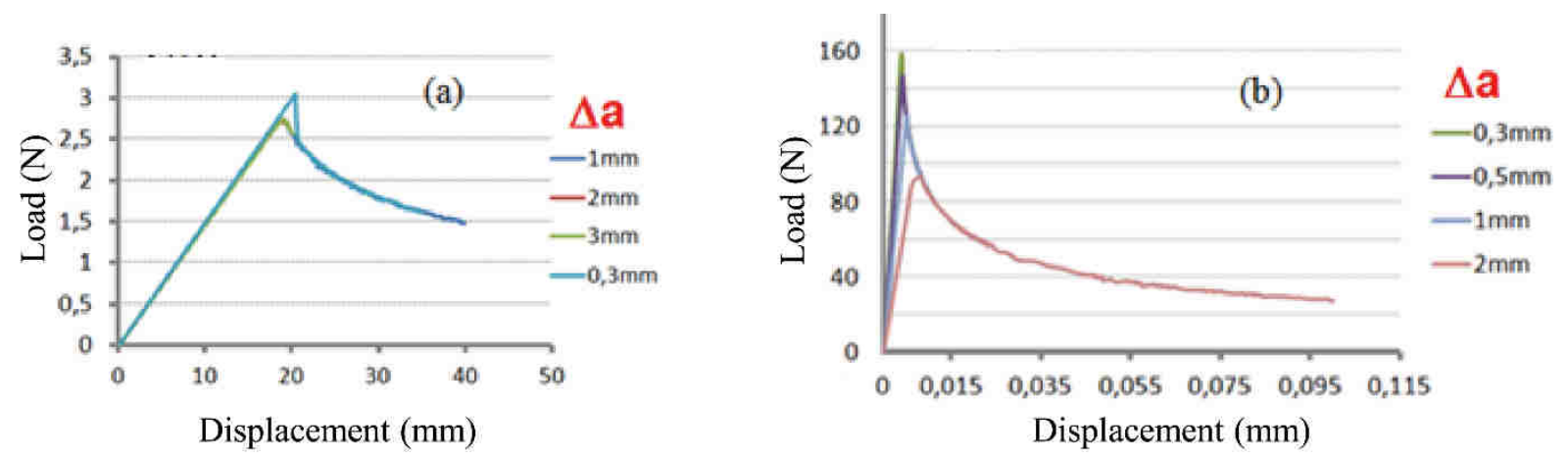

Fig.11. Finite element simulations results: numerical load-displacement curves for the long beam (a) and the short beam (b) with 4 different values of defects.

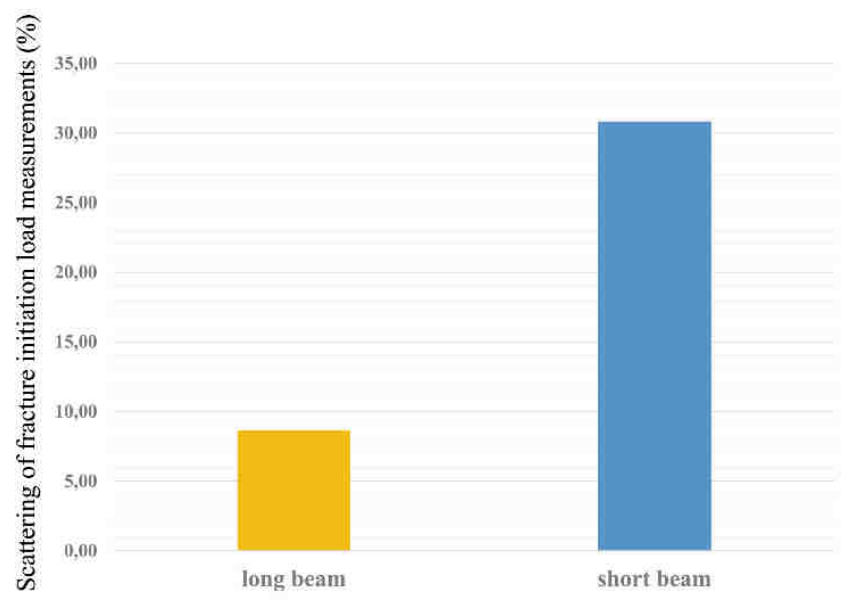

Figure 12. Scattering of fracture initiation load measurements calculated for different values of defects for the long and short beam FIT configurations. 
The scattering of fracture initiation load measurement is described in Figure 12. The results indicate that when the long deformable beam is used, the influence of the numerical defects introduced on the scattering is reduced. The FIT test seems to be less sensitive and more accurate to measure the fracture initiation load. The FIT test proposed seems to be able to decrease the uncertainty on the fracture initiation load determination. As the concept of the FIT test (Flexible Initiation Test) is validated numerically, the long beam geometry is chosen for the experimental campaign. 


\section{Experimental validation of the FIT test}

\subsection{Design and technology of the experimental setup:}

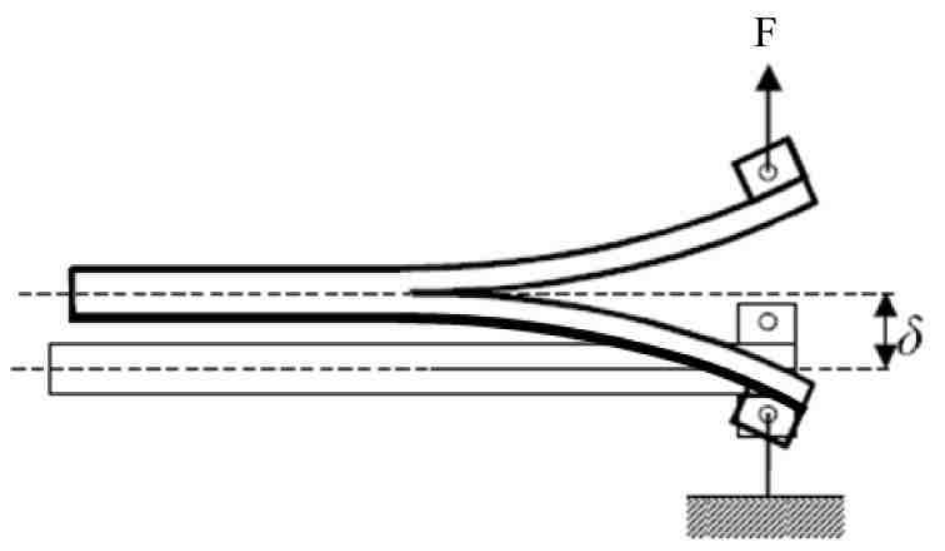

Figure13. Standard DCB test setup.

In the FIT test proposed, to remain in pure mode I, the specimen is positioned vertically, in order to minimize the influence of gravity as developed in Marzi et al. [26]. Because in standard DCB quasi-static tests, one side of the sample is fastened to the tensile test machine by a pivoting link while a vertical force is applied on the other side of the sample. In this configuration, an effect of the weight of the device appeared during the vertical movement of the test on the tensile testing machine, even more in the case of long deformable support beams as in the flexible initiation test, as shown in Figure 13. In this configuration, the mode II of failure can be activated, and the bonding joint is solicited not only in mode I but also in mixed mode (I+II). The vertical positioning of the FIT test is described in Figure. 14. 


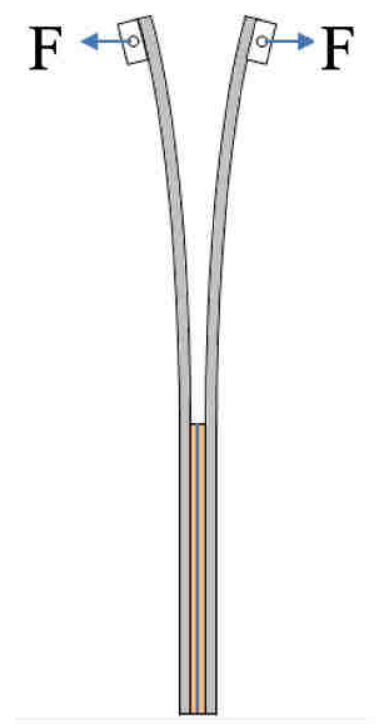

Figure 14. Flexible initiation test with the sample in vertical position.

The experimental device is designed and made in our laboratory. A linear displacement device from RK-Rose-Krieger [27] is used to set the sample in vertical position with symmetrical displacement of each deformable support beam. This device (Figure 15) is composed of two linear carriages, a right-hand and a left-hand thread allowing a symmetric displacement, with two guides and a spindle clamping to control the symmetrical displacement of the carriage. During the test, two measurements are essential: the displacement $\delta$ and the applied load $\mathrm{F}$ at the tip of the deformable support beams. That is why the system described above is equipped with displacement and load sensors. In the flexible initiation test, two load cells and one displacement sensor of LVDT (Linear Variable Differential Transformer) type are used. 


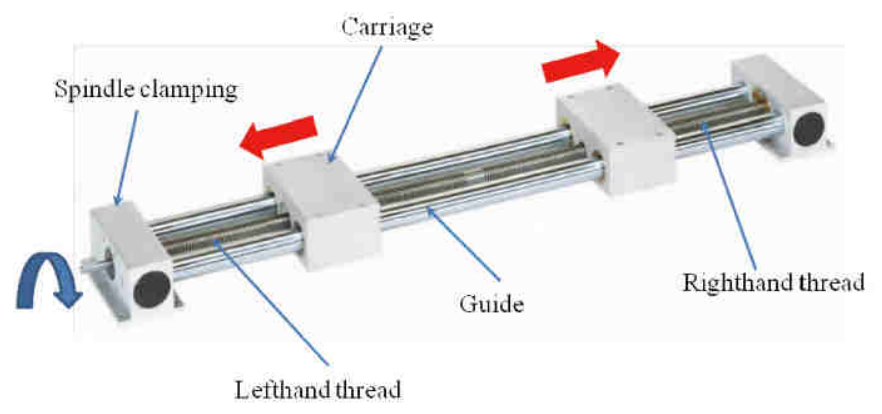

Figure 15. Linear horizontal unit to convert a rotation into a symmetrical displacement [27].

The load cells are mounted on each carriage. This miniaturized sensor (Burster model 8411) is able to measure load ranges from 0 to $200 \mathrm{~N}$ with an accuracy deviation below $0.5 \%$. The flexible support beams are linked to an aluminum clevis connected to the load sensors by a ball joint connection, in order to have an isostatic system and to keep the imposed load in a horizontal direction during the test. The displacement sensor is clamped on the frame and measures the displacement of one of the carriages. This sensor is able to measure displacement in the range of 0 to $40 \mathrm{~mm}$ with an accuracy deviation below $0.5 \%$. Figure 16 describes the final experimental device of the flexible initiation test. 


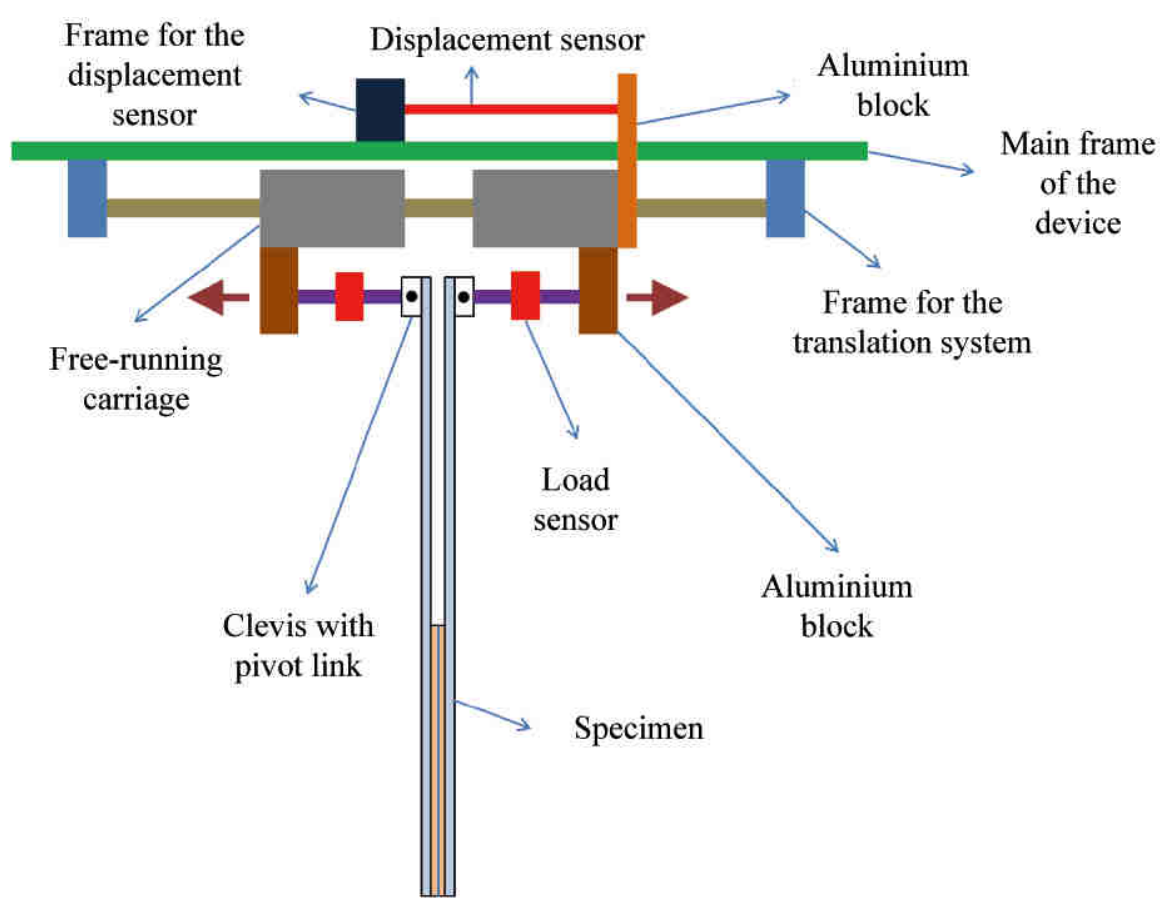

Figure. 16. Drawing of the flexible initiation test device.

\subsection{Material and geometry of the bonded samples:}

In these experimental investigations, three types of adhesive are tested: an adhesive with a ductile mechanical behavior (Scotch-Weld ${ }^{\text {TM }}$ 3M 2216 B/A Epoxy Adhesive [21]) and two adhesives with a brittle mechanical behavior (The Permabond 910 cyanoacrylate adhesive [36] and Araldite ${ }^{\circledR}$ AV138/HV998 epoxy adhesive [22]). The samples are composed of two deformable support beams made in aluminum 2017A with the same geometry. In this case, the adhesive behavior is characterized on an aluminum substrate. Therefore, to simplify samples fabrication, the support beam and the substrate were machined in a single part (Figure 17). Two different geometries are used in the experiments because for the short length 
of the support beam the measured load exceed the load cell limit. That's why, in this case the width of the support beam is decreased in order to remain in the load cell range.

- The first sample geometries (Figure 17(a)) has been used for the Permabond 910 cyanocrylate adhesive.

- The second sample geometries (Figure 17(b)) has been used for the Araldite ${ }^{\circledR}$ AV138/HV998 and the Scotch-Weld ${ }^{\mathrm{TM}}$ Epoxy Adhesive 2216 B/A.

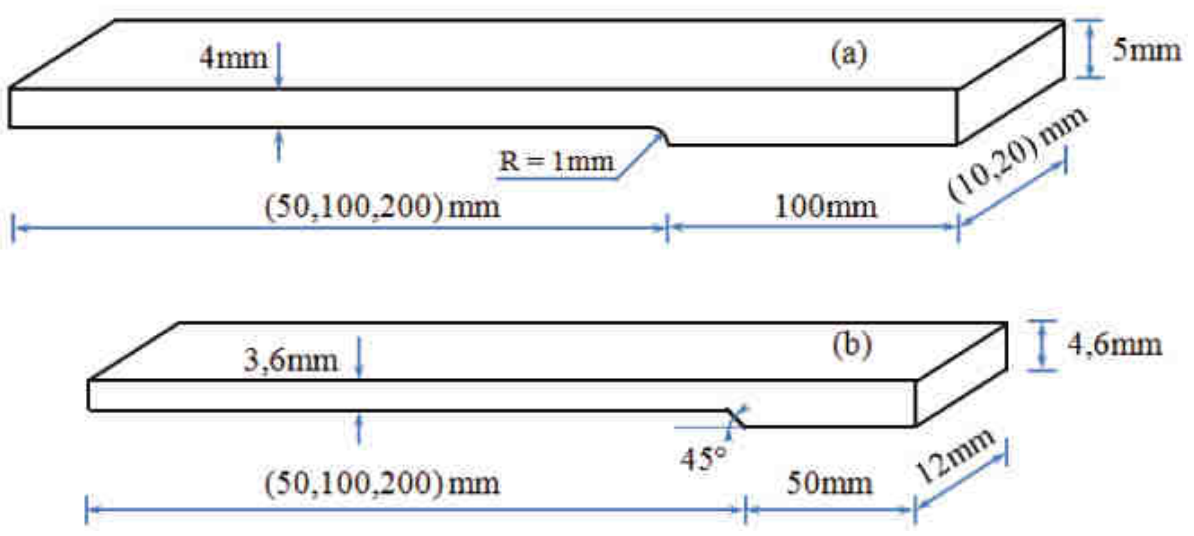

Figure. 17. Geometry of the bonded specimens. (a) Geometries used for the Permabond 910 cyanocrylate adhesive. (b) Geometries used for the Araldite ${ }^{\circledR}$ AV138/HV998 and the Scotch-Weld ${ }^{\mathrm{TM}}$ Epoxy Adhesive 2216 B/A. 

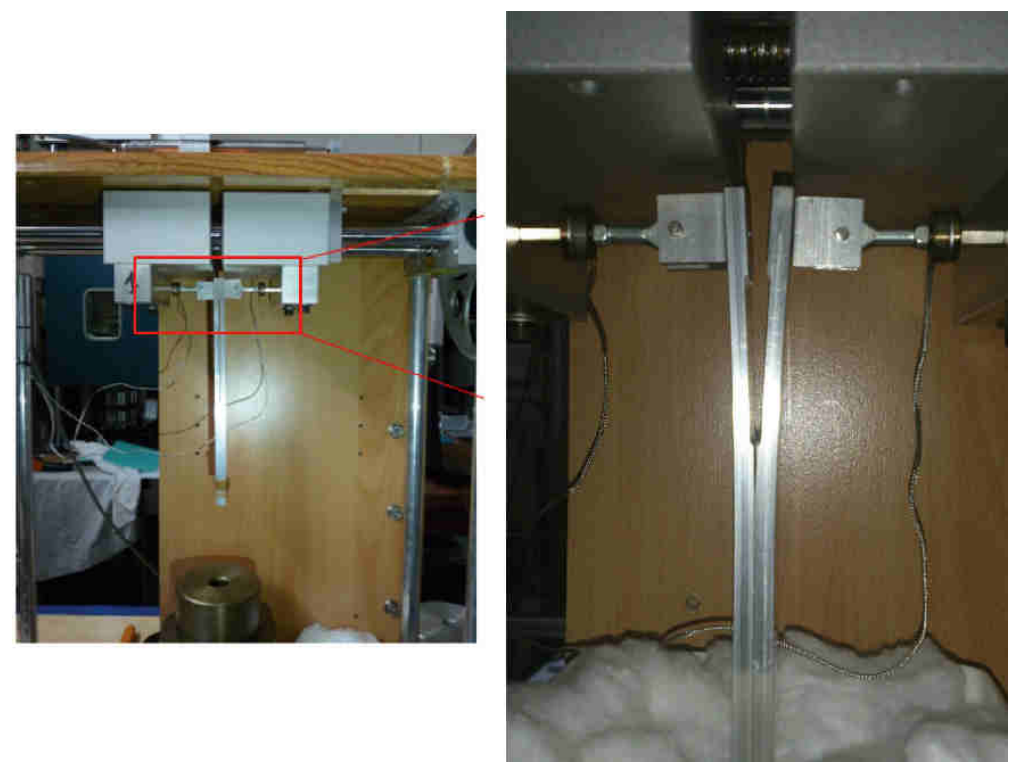

Figure 18. Experimental device for the flexible initiation test.

For each sample geometry, three different deformable support beam lengths are tested: 50 $\mathrm{mm}, 100 \mathrm{~mm}$ and $200 \mathrm{~mm}$. Before bonding, the bonded zone was sanded with sandpaper, then cleaned with acetone and oven dried. The thickness of the adhesive was calibrated at $0.1 \mathrm{~mm}$ using the diameter of a fluoro-carbonate fishing wire. The fishing line is along the width of the sample at a safe distance of the edge where the initiation occurred. All the tests were performed in quasi static condition $\left(5 \mathrm{~mm} \cdot \mathrm{min}^{-1}\right)$, the strain rate is controlled by a belt drive system ensuring a constant rotation speed. The flexible initiation test device with a mounted bonded sample is described in Figure 18.

\subsection{Experimental results}

For each test, five samples are tested, and the experimental force-displacement curves are measured. Figure 19 describe the curves measured for each beam length considered, and we 
can observe that the scattering decrease with the increase of the beam length and the average

value decrease quasi linearly with the increase of the beam length. As explained previously the FIT test stays in linear domain and allows to decrease scattering in measurement. Critical initiation load measurements become more accurate and less sensitive. The fracture initiation load is measured and the average value is calculated. Then, the scattering (standard deviation in \%) around the average value is calculated, the values are reported in table 3.

Table 3 Experimental results of the critical initiation load measured for three different adhesives with three different FIT test configuration (three beam lengths). Each scattering of measurement are compared and reported in Figure 20.

\begin{tabular}{|c|c|c|c|c|}
\hline \multirow{2}{*}{ Adhesives } & \multirow{2}{*}{$\begin{array}{c}\text { Flexible Beam length } \\
\text { (20 mm width })\end{array}$} & \multicolumn{3}{|c|}{ Critical initiation load } \\
\hline & & Average Load (N) & Standard deviation $(\mathbf{N})$ & Standard deviation (\%) \\
\hline Permabond 910 & $50 \mathrm{~mm}$ (10 mm width) & 104.627 & 22.774 & 21.767 \\
\hline \multirow{2}{*}{ cyanocrylate } & $100 \mathrm{~mm}$ & 120.464 & 11.023 & 9.151 \\
\hline & $200 \mathrm{~mm}$ & 68.914 & 1.097 & 1.591 \\
\hline Araldite $\AA$ & $50 \mathrm{~mm}$ & 81.150 & 12.629 & 15.188 \\
\hline \multirow{2}{*}{ AV138/HV998 } & $100 \mathrm{~mm}$ & 43.336 & 4.524 & 10.439 \\
\hline & $200 \mathrm{~mm}$ & 19.861 & 1.276 & 6.428 \\
\hline Scotch-Weld ${ }^{\mathrm{TM}}$ Epoxy & $50 \mathrm{~mm}$ & 155.687 & 6.016 & 3.864 \\
\hline \multirow{2}{*}{ Adhesive 2216 B/A 3M } & $100 \mathrm{~mm}$ & 80.818 & 2.711 & 3.354 \\
\hline & $200 \mathrm{~mm}$ & 44.959 & 1.229 & 2.735 \\
\hline
\end{tabular}



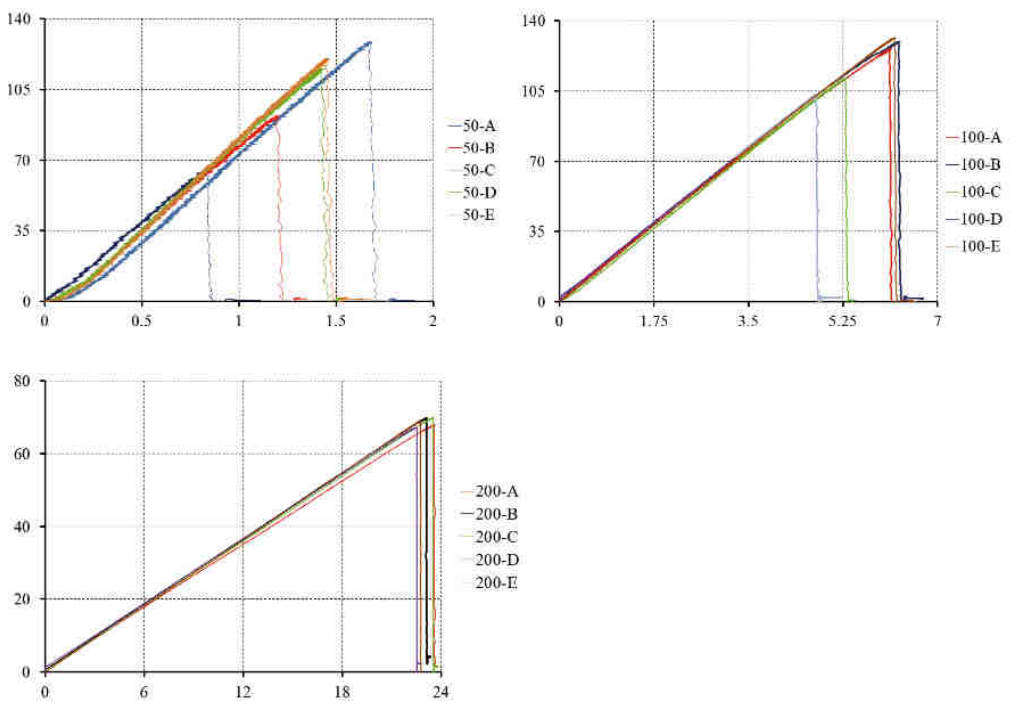

Figure 19 Experimental force-displacement curves measured with the FIT test with three different beam length on cyanoacrylate bonded samples.

The scattering evolution, for the three adhesives and the three lengths, is proposed in Figure 20. The experimental results allow us to validate the efficiency of the new Flexible Initiation Test (FIT) to reduce scattering measurement for a solicitation in mode I. Results show that the longer the deformable support beams are, the lower the scattering is. The scatter decreases significantly for the adhesives with a brittle mechanical behavior (Permabond 910 and Araldite AV138/HV998), but not for the adhesive with a ductile mechanical behavior (3M $2216 \mathrm{~B} / \mathrm{A})$. 


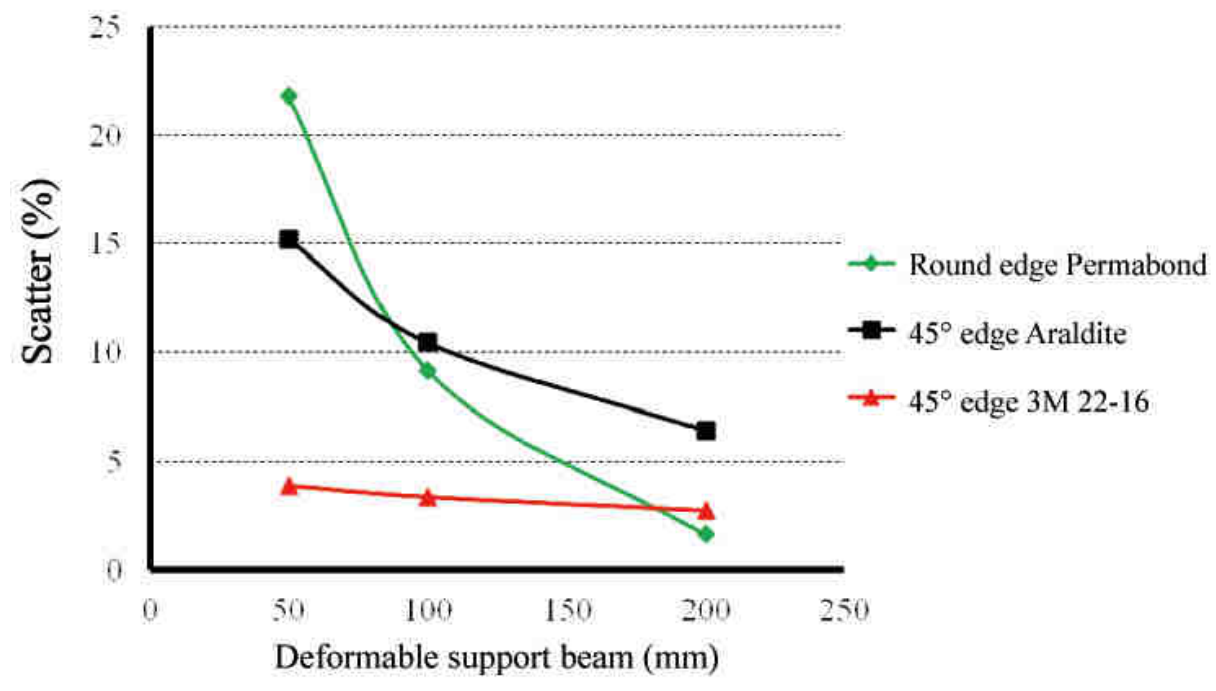

Figure 20. Evolution of scattering (defect sensitivity) as a function of the deformable support beam length for the three adhesives tested. 


\section{FIT test: application on reinforced direct bonding}

Then, after the experimental validation of the FIT test, experiments are led on direct-bonded fused silicate samples. The five samples have been designed as two reinforced direct-bonded blades with a chamfered edge at $45^{\circ}$ with a final dimension of $50 \mathrm{~mm} \times 20 \mathrm{~mm} \times 1 \mathrm{~mm}$, as related in Figure 21.

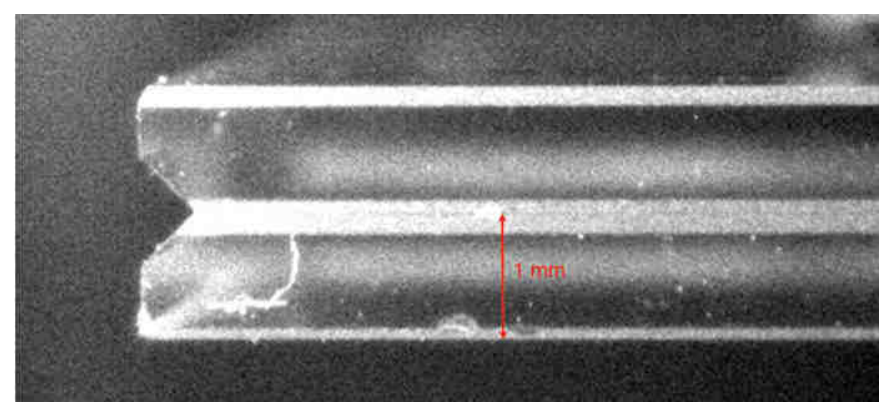

Figure 21. Optical microscope image of the reinforced direct-bonded fused silicate sample.

The sample is constituted of two fused silicate blades (length $50 \mathrm{~mm}$ and width $20 \mathrm{~mm}$ ) with a thickness equal to $1 \mathrm{~mm}$. Due to the polishing process a chamfered edge is machined on each edge of the blade. The grey zone represents the projection of the chamfered edge. 

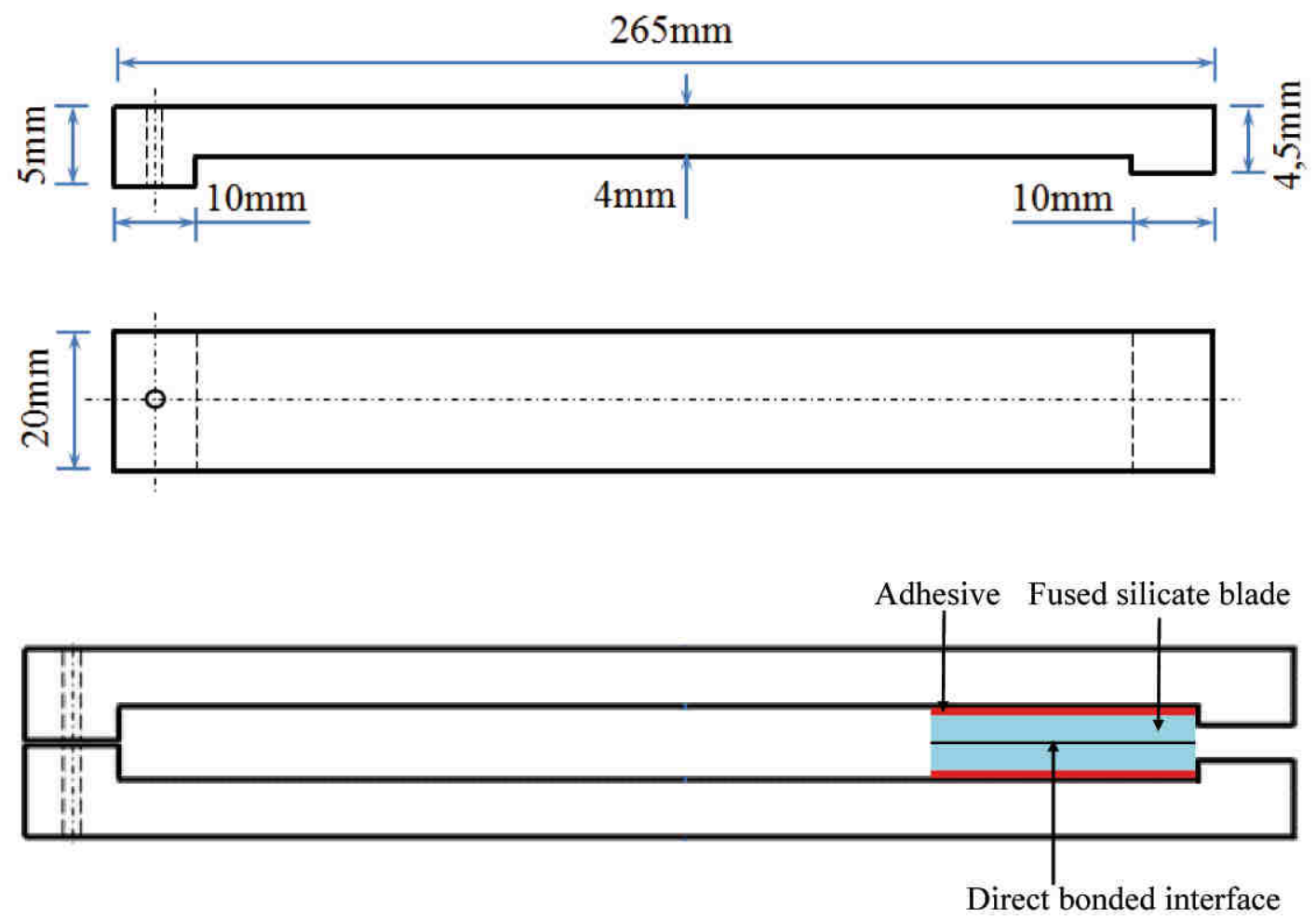

Figure 22. Picture of bonded sample geometries for direct bonding characterization.

In these experiments, as in experiments presented in the previous section, the deformable aluminum 2017 support beams were designed with a specific geometry allowing the direct bonded glass samples to be bonded on the optimal length beam, as described in Figure 22 . Direct bonded samples were bonded with the $3 \mathrm{M}$ adhesive, the adhesive thickness being controlled, as described in Figure 23. 

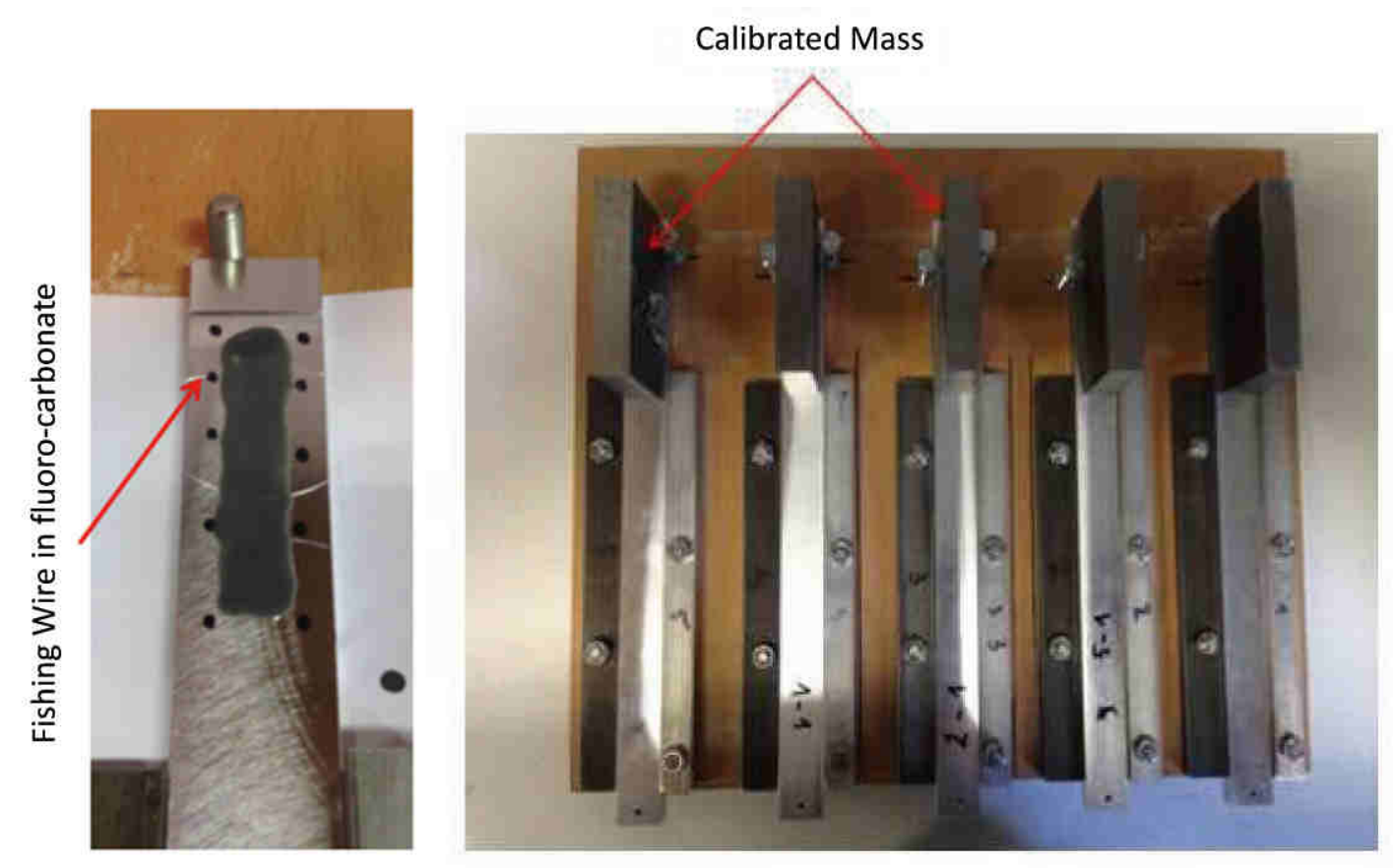

Figure 23. Device to bond direct-bonded samples on deformable aluminum support

beams.

The fracture initiation load is measured for each direct-bonded sample. Experimental results as the average value and the standard deviation of the critical initiation load are reported in Table 4. Figure 24 presents the evolution of the scattering of the fracture initiation load measurements for the three different experimental bench used to characterize reinforced direct-bonded assemblies: the peel test, the cleavage test and the FIT test. In conclusion, the FIT test is efficient to reduce scattering of measurement and to improve reinforced direct bonding characterization. 
Table 4. Experimental results of the critical initiation load measured for direct bonded samples with a $45^{\circ}$ chamfered edge.

\begin{tabular}{|c|c|c|}
\hline \multicolumn{2}{|c|}{ Critical initiation load of the reinforced direct bonding interface } \\
\hline Average Load (N) & Standard deviation (N) & Standard deviation (\%) \\
\hline 4.738 & 0.423 & 8.929 \\
\hline
\end{tabular}

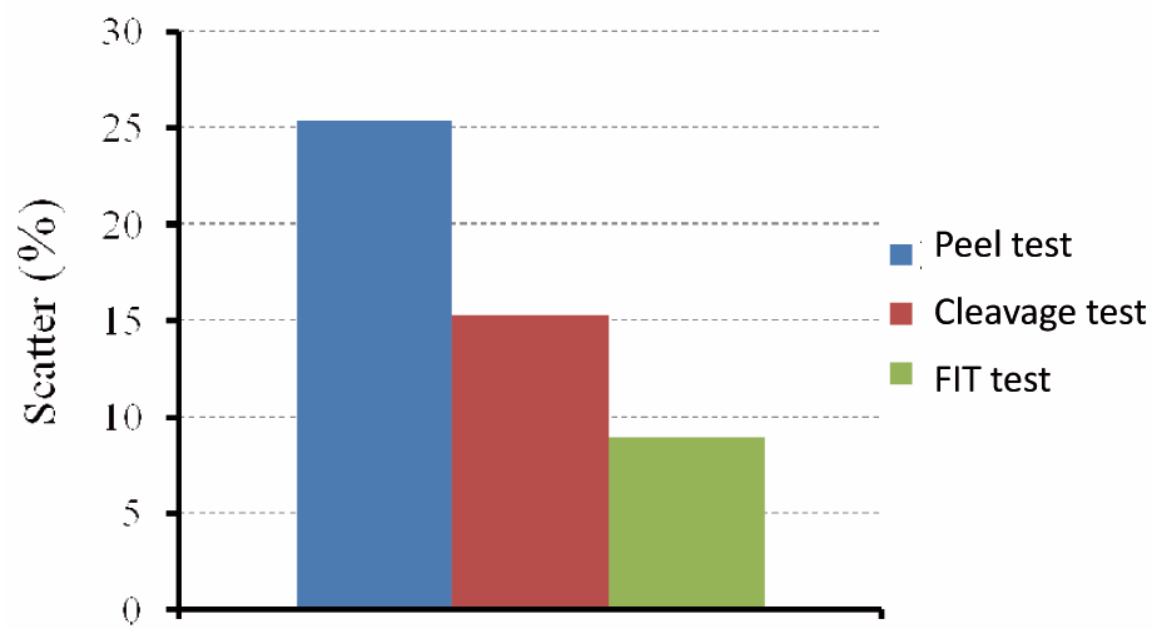

Figure 24. Scattering of fracture initiation load measurements for peel test, cleavage test and

FIT test. 


\section{Conclusions and Prospects:}

In this paper, a new test allowing scattering of critical fracture initiation load measurements to be reduced has been described. This new test, named Flexible Initiation Test (FIT), used deformable support beams bonded to samples (the sample is composed of substrate and adhesive). The load is symmetrically imposed and measured at the tip of these support beams, and the displacement is measured. First, a numerical analysis has been performed to validate a first configuration. Then, an experimental campaign was carried out in order to validate the concept in varying the deformable support beam length for three different adhesives (brittle and flexible). Results were showed that a long support beam $(200 \mathrm{~mm})$ allows scattering of the fracture initiation load measurements to be reduced, in particular for the adhesives with a brittle mechanical behavior (Araldite, Cyanoacrylate and Direct Bonding). In conclusion, this Flexible Initiation Test is more sensitive and more accurate to characterize fracture initiation in mode I. A forthcoming paper will describe the FIT tests used to analyze some classical stress fracture criteria (point stress, average stress) and a coupled stress and energy failure criterion proposed by Leguillon [28]. In future investigation, the FIT will be extended to different modes of fracture (mode II, mixed-mode (I+II)) and applied to different adhesives. 


\section{References}

[1] Adams RD, Comyn J, Wake WC. Structural adhesives joints in engineering. 2nd ed. Chapman \& Hall; 1997.

[2] Tong L, Steven GP. Analysis and design of structural bonded joints. Kluwer; 1999. https://doi.org/10.1007/978-1-4615-5133-1

[3] Adams RD. Adhesive bonding: science, technology and applications. Bristol: Woodhead Publishing Ltd; 2005.

[4] Ripling EJ, Mostovoy S, Patrick RL. Measuring fracture toughness of adhesive joints. Mater Res Stand (ASTM Bull) 1964; 4:129-34.

[5] Berry JP. Determination of Fracture Surface Energies by the Cleavage Technique. Journal of Applied Physics 1963; 34:62-68. http://dx.doi.org/10.1063/1.1729091

[6] McDevitt NT, Baun WL. The Three-Point Bend Test for Adhesive Joints. Adhesive joints

- formation, characteristics and testing edited by K. L. Mittal, Plenum Press, New York, $1984 ; 381-394$.

[7] Arcan M., Hashin Z., Voloshin A. Method to produce uniform plane-stress states with applications to fiber-reinforced materials. Experimental Mechanics1978, 18(4):141-146. https://doi.org/10.1007/BF02324146 
[8] Cognard JY, Davies P, Sohier L, Créac'hcadec R. A study of the non-linear behaviour of adhesively-bonded composite assemblies. Composite Structures 2006; 76:34-46. https://doi.org/10.1016/j.compstruct.2006.06.006

[9] Cognard JY, Créac'hcadec R, Sohier L, Davies P. Analysis of the nonlinear behavior of adhesives in bonded assemblies-Comparison of TAST and Arcan tests. International Journal of Adhesion and Adhesives 2008; 28:393-404. https://doi.org/10.1016/j.ijadhadh.2008.04.006

[10] Cognard JY, Créac'hcadec R. Analysis of the Non-linear Behavior of an Adhesive in Bonded ssemblies Under Shear Loadings. Proposal of an Improved TAST. Journal of Adhesion Science and Technology 2009; 23:1333-1355. http://dx.doi.org/10.1163/156856109X432956

[11] Davies P, Sohier L, Cognard JY, Bourmaud A, Choqueuse D, Rinnert E, Créac'hcadec R. Influence of adhesive bond line thickness on joint strength. International Journal of Adhesion and Adhesives 2009; 29:724-736. http://dx.doi.org/10.1016/j.ijadhadh.2009.03.002 [12] Epoxy resin Araldite $^{\circledR} \quad 420$ Huntsman technical files, http://www.huntsman.com/advanced_materials/Media\%20Library/global/files/EUR_Adhesiv es\%20Core\%20Range\%20-\%20Adhesives_Epoxy_Araldite_Bonding_Resin.pdf; [accessed 20.04.17]. 
[13] Cognard JY, Davies P, Gineste B, Sohier L. Development of an improved adhesive test method for composite assembly design. Composites Science and Technology 2005; 65(34):359-368. http://dx.doi.org/10.1016/j.compscitech.2004.09.008

[14] Kendall K. Molecular adhesion and its applications. Kluwer Academic Publishers 2001.

[15] Ventosa C, Rieutord F, Libralesso L, Morales C, Fournel F, Moriceau H. Hydrophilic low-temperature direct wafer bonding. J. Appl. Phys. 2008; 104:123524-1 123524-12.

[16] Cocheteau N, Maurel-Pantel A, Lebon F, Rosu I, Prieto E, AitZaid S, Savin De Larclause I, Salaün Y. Mechanical characterization of direct bonded silica surfaces. Journal of Adhesion $\begin{array}{llll}\text { Science } & \text { and } & \text { Technology } & \text { 2014; }\end{array}$ http://dx.doi.org/10.1080/01694243.2013.876138

[17] Cocheteau N, Maurel-Pantel A, Lebon F, Mazerolle F, Rosu I, AitZaid S, Savin De Larclause I. Influence of roughness on mechanical strength of direct bonded silica and Zerodur ${ }^{\circledR}$ glasses. International Journal of Adhesion and Adhesives 2016; 68:87-94. http://dx.doi.org/10.1016/j.ijadhadh.2016.02.00

[18] Liao G., Shi T., Lin X., Ma Z. Effect of surface characteristic on room-temperature silicon direct bonding, Sensor and Actuators A, Physical. 2010; 158:335-341. https://doi.org/10.1016/j.sna.2010.01.025 
[19] Kissinger G., Kissinger W. Void-free silicon-wafer-bond strengthening in the $200-400^{\circ} \mathrm{C}$ range, Sensor and Actuators A, Physical. 1993; 36(2):149-156. https://doi.org/10.1016/09244247(93)85009-5

[20] Cyanoacrylate adhesive Permabond 910 technical files, http://www.permabond.com/wpcontent/uploads/2016/04/910_TDS.pdf; 2017 [accessed 20.04.17]. Scotch-Weld ${ }^{\mathrm{TM}}$ $3 \mathrm{M}$ 2216 $\mathrm{B} / \mathrm{A}$ technical files, http://multimedia.3m.com/mws/media/3191840/2216-ba-fiche-technique-colle-3mtm-scotchweld.pdf?\&218TyEVuQEcuZgVs6EVs6E666666--; 2017 [accessed 20.04.17].

[22] Araldite $\AA$ AV 138M-1 / Hardener HV 998 technical files, http://commerce.sage.com/bag/upload//site/default/FT/Fran $\% \mathrm{C} 3 \%$ A7ais/Araldite/Araldite $\% 2$ 0AV\%20138M-1\%20+\%20Hardener\%20HV998.pdf; 2017 [accessed 20.04.17].

[23] Da Silva LFM, Rodrigues T, Figueiredo MAV, De Moura M, Chousal JAG. Effect of adhesive type and thickness on the lap shear strength. The journal of adhesion 2006; 82(11):1091-1115. http://dx.doi.org/10.1080/00218460600948511

[24] Turon A, Dávila CG, Camanho PP, Costa J. An engineering solution for mesh size effects in the simulation of delamination using cohesive zone models. Engineering Fracture Mechanics 2007; 74(10):1665-1682. https://doi.org/10.1016/j.engfracmech.2006.08.025 
[25] Moës N, Belytschko T. Extended finite element method for cohesive crack growth.

Engineering Fracture Mechanics 2002; 69:813-833. https://doi.org/10.1016/S00137944(01)00128-X

[26] Marzi S, Biel A, Stigh U. On experimental methods to investigate the effect of layer thickness on the fracture behavior of adhesively bonded joints. International Journal of Adhesion and Adhesives 2011; 31(8):840-850.https://doi.org/10.1016/j.ijadhadh.2011.08.004

[27] Symmetrical linear displacement system technical files, https://www.rk-rosekrieger.com/fileadmin/catalogue/lineartechnik/fr/lt_copas_fr.pdf; 2017 [accessed 20.04.17].

[28] Leguillon D. Strength or toughness? A criterion for crack onset at a notch. European

Journal of Mechanics A/Solids 2002; 21:61-72. https://doi.org/10.1016/S09977538(01)01184-6 